\title{
RETOSSIGMOIDOSCOPIA EM PACIENTES SINTOMÁTICOS
}

DESCRITORES - Colonoscopia. Sigmoidoscopia. Proctoscopia.

O emprego da retossigmoidoscopia na prática clínica remonta à antigüidade. $\mathrm{Na}$ época de Hipócrates, já existiam tubos rígidos para o exame dos segmentos distais do intestino ${ }^{(2)}$.

Na década de 1970, a colonoscopia foi incorporada ao arsenal diagnóstico das afecções colorretais. Embora possibilite o exame de toda a extensão do cólon, esse procedimento é mais invasivo e requer preparo intestinal adequado.

A condução da investigação diagnóstica de pacientes sintomáticos a partir de exames menos agressivos é plenamente defensável. Nesse caso, a retossigmoidoscopia estaria indicada como exame inicial e, na dependência de seu resultado, ao paciente seria recomendada uma colonoscopia.

No entanto, suponhamos um paciente com sangramento intestinal, que é submetido a uma retossigmoidoscopia. Caso esse primeiro exame seja normal, a colonoscopia para elucidação diagnóstica se impõe. Se for constatada a presença de câncer colorretal, a colonoscopia é imperativa para detecção de lesões sincrônicas. O mesmo raciocínio é válido se a retossigmoidoscopia revelar a existência de pólipos. Se, porventura, uma doença inflamatória for diagnosticada, o passo seguinte é a realização de colonoscopia para avaliação da extensão da doença.
Então por que indicar a retossigmoidoscopia para um paciente sintomático?

A esses fortes argumentos, associam-se os achados de BINDA et al. ${ }^{(1)}$ que, avaliando uma série de pacientes sintomáticos encaminhados à colonoscopia, detectaram que, apesar de as lesões nos segmentos distais serem mais freqüentes, é possível haver neoplasias nos segmentos proximais em indivíduos cujos segmentos distais são normais. Esse fenômeno foi particularmente evidente em indivíduos com mais de 50 anos de idade. Nesse grupo, 1 em 52 pacientes que não tinham lesões neoplásicas no reto e sigmóide, apresentavam-se com lesões avançadas nos segmentos proximais e três quartos dos pacientes com lesões proximais apresentavam os segmentos distais normais.

Progressivamente, torna-se mais evidente que a colonoscopia é o exame inicial de eleição para pacientes sintomáticos, com suspeita de lesões colorretais. Por outro lado, a retossigmoidoscopia flexível, por ser segura, bem tolerada e com impacto direto na redução da mortalidade pelo câncer colorretal, permanece como importante recurso no rastreamento do câncer em pacientes assintomáticos.

Marcelo AVERBACH*

Averbach M. Rectossigmoidoscopy in symptomatic patients. Arq Gastroenterol. 2007;44(1):1.

HEADINGS - Colonoscopy. Sigmoidoscopy. Proctoscopy.

\section{REFERÊNCIAS}

. Binda V, Pereira-Lima J, Nunes CA, Falkemberg LT, Azambuja DB, Cruz JV. Is there a role for sigmoidoscopy in symptomatic patients? Arq Gastroenterol. 2007;44:2-7.

2. Keele KD. The evolution of clinical methods in medicine. London: Pitman; 1963. 